\title{
The Influences of Multiple Factors in the Success of Strategic Planning in Project Management
}

\author{
Stacy Lynch ${ }^{1}$ \\ ${ }^{1}$ University of St. Augustine, Saint Augustine, USA \\ Correspondence: Stacy Lynch, University of St. Augustine, Saint Augustine, FL 32086, USA.
}

Received: February 2, 2021

Accepted: March 15, 2021

Online Published: April 2, 2021

doi:10.5430/jms.v12n1p31

URL: https://doi.org/10.5430/jms.v12n1p31

\begin{abstract}
Strategic planning is a process that involves informed dialog among the committee members over a period of time such that a consensus emerges as a natural outcome. In this paper, the multiple factors influencing success of strategic planning has been studied. Key success factors in strategic planning of project management contain such activities that must be performed if the organization intends to achieve its long-term targets. A large majority of enterprises only have a handful of key success factors. Nonetheless, even if one of these success factors is not executed accurately and precisely, the enterprises' competitive strategy might be threatened. The key success factors in achieving project management excellence also apply to other types of organizations, including those which have not thoroughly implemented their project management systems. Though most organizations are sincere in their efforts to thoroughly implement their systems, stumbling stones are inevitable and have to be overcome. The statistical population of this research is composed of managers, consultants, and experts involved in the strategic planning in project management. According to the research results, the involvement of top management, involvement of team personnel, knowledge of the top management of strategic planning, and organizational culture are the most effective factors of strategic planning.
\end{abstract}

Keywords: strategic planning, factors, project management

\section{Introduction}

Managers are required to direct their organizations towards an unknown future, and their success in crossing this turbulent path depends on their ability to predict and have understanding of their surrounding world, which is complicated and full of instabilities, bureaucracies, political movements, and inevitable facts that may constitute surprising challenges to the management of organizations. Such surprises may be due to the rapid changes and developments of technology, increase in population, and demands for several products, and they may be considered as a threat for the reduction of demands or increase in prices. Moreover, events such as wars, and socioeconomic crises causing problem in the current system of products supply and distribution make the forecast of needs considerably difficult (Alvani, 1995: 14).

Strategic planning system creates a very effective and suitable communicative channel in the different levels of organizational pyramid. Most organizations that prepared strategic planning acknowledge that the process of planning has a great role in their managerial understanding as management training courses do (Sha'ni, 2004: 38). Strategic planning is a process used for the mobilization of organization's resources, unification of organizational efforts for achieving long-term objectives and missions based on internal and external limits. Another definition introduces strategic planning as a plan for achieving long-term objectives of an organization and required activities for their realizations (Freeman \& Stoner, 1996). Elanis Consulting Group argues that, "strategic planning is a systematic effort for making essential decisions and performing important activities, and focusing on the future to decide which organization we are, what we do, and if we perform them correctly (Prathibha \& Kevin, 2010). In other words, a strategic plan can improve operation, promote the understanding of members of the objectives, and create a forward-looking thought based on mutual understanding of organizational mission. The cooperation of the members of an organization having common assumptions on objectives will be very efficient and effective.

\section{Literature Review}

The first implementation task of any strategic objective should be to develop a detailed implementation plan that 
includes responsibilities, resources, and timeline. Ownership and support are important to successful implementation. Considering the factors identified by the different researchers studying the success of strategic planning, the following factors effective in the success of strategic planning have been recognized:

\subsection{Top Managers' Involvement}

The most important prerequisite for the establishment of a participatory management system is the diligent support of top management of the establishment of such a system. If the diligent support of top management continues, the success of this system is guaranteed, otherwise it is not recommended to develop such a system in an organization, in which the top management does not believe in this system. Top management must create an appropriate and effective environment for strategic planning. The other role of the top management of an organization is to ensure the consistence of the forecasted planning system with the characteristics of the related organization. Therefore, it is required that the top management of organization has a correct understanding of strategic planning comprehensively. Strategic planning has a special status among the responsibilities of top management, in such a way that an organization lacking strategic planning cannot be administered appropriately under competition conditions (Sha'ni, 2004: 148).

Top management must report its superior authorities in regular intervals about the results of the activities performed for strategic planning. The increase in the participation of top executive officers of an organization in decision making in proportion to its diligence enriches the content of the developed plan to a greater extent (Shokri, 2001: 46).

\subsection{The Knowledge of Top Management}

Strategic planning determines the direction and destination of an organization. When the members of an organization feel that they can play an effective role in the development of strategic planning, they work with higher motivations and commitment on their organization, and they understand which objectives are sought by the organization (Shokouhi, 2002: 132).

The allocation of resources is one of the main responsibilities of management. As the resources of each organization are limited and investment in strategic planning is very expensive, it is therefore very important top management to have knowledge of strategic planning so that it can evaluate recommendations systematically. Moreover, the knowledge of strategic planning helps top management to evaluate the profits that may be earned from investments, and creates expectations more realistic than those ones strategic planning creates (Bruce \& Longden, 2004: 38).

\subsection{The Involvement of Team Personnel}

Personnel in decision-making ensures them that the management trusts in their ability and potentials. The participation of personnel improves their power for accepting responsibilities, causes they have occupational satisfaction, and motivates them for meeting organizational objectives, since they feel united with their organization. Moreover, it helps them to have freedom of action, feel satisfied mentally and realize that their opinions are heard (Sa'adat, 1993: 202). Executive officers and authorities of organizations should encourage the personnel of their organization to develop their ideas, skills, and motivate them successfully (Haines, 1997: 124).

\subsection{Organizational Culture}

One of the effective factors spreading strategic planning is organizational culture. Similar to human being, any organization has its own personality. In general, when several persons work together, a culture is created. The managers of an organization should develop a culture for attracting the attention of the personnel to strategic planning (Richard, 2005). Denison conducted a series of management studies and provided a model showing the relation between environmental needs and strategic focus of an organization on the one hand, and the organizational culture consistent with this relation. 
Table 1. Factors and indices that are effective in the success of strategic planning

\begin{tabular}{|c|c|c|}
\hline Factors & Indices & \\
\hline \multirow{5}{*}{$\begin{array}{l}\text { Top Ma } \\
\text { Knowledge }\end{array}$} & $\checkmark$ & The governance of strategic thinking among senior manager \\
\hline & $\checkmark \quad$ plann & $\begin{array}{l}\text { Holding various meetings for senior managers to introduce them with strategic } \\
\text { ning knowledge }\end{array}$ \\
\hline & $\checkmark$ & Acceptance of importance of strategic planning in the success of the companies \\
\hline & $\checkmark$ & Scientific level of senior Managers in strategic planning knowledge \\
\hline & $\checkmark$ & Skill level of senior Managers in strategic planning process \\
\hline \multirow{10}{*}{$\begin{array}{l}\text { Top Managers' } \\
\text { Involvement }\end{array}$} & $\checkmark$ & Exchange of information between project team and Senior Managers \\
\hline & $\checkmark \quad$ the p & $\begin{array}{l}\text { Identifying the desired key issues of the Senior Managers from the beginning of } \\
\text { roject }\end{array}$ \\
\hline & $\checkmark$ & Attendance of the Senior Managers in project team \\
\hline & $\checkmark \quad$ deve & $\begin{array}{l}\text { Support and agreement of the Senior Managers of the company of the } \\
\text { lopment of the strategy }\end{array}$ \\
\hline & $\checkmark$ & Supervision of Senior Managers of proper implement of the project \\
\hline & $\checkmark$ & Considering the desired key issues of the Senior Managers in the planning \\
\hline & $\checkmark$ & Establishment of proper and effective atmosphere to strategic planning \\
\hline & $\checkmark \quad$ planr & $\begin{array}{l}\text { Proper understanding of the Senior Management of the nature of strategic } \\
\text { ning }\end{array}$ \\
\hline & $\checkmark \quad$ imple & $\begin{array}{l}\text { Active involvement of management staff from the beginning of the planning to } \\
\text { ementation }\end{array}$ \\
\hline & $\checkmark$ & Insight of Senior Management about future and potentialities of the organization \\
\hline \multirow[t]{9}{*}{ Team involvement } & $\checkmark \quad$ exist & $\begin{array}{l}\text { Training of the general strategies and objectives of the organization and internal } \\
\text { ing problems to the personnel }\end{array}$ \\
\hline & $\checkmark$ & Informing the related organizational units of stages of project process \\
\hline & $\checkmark$ & Training of the process, methodologies and frameworks of the strategic planning \\
\hline & $\checkmark \quad$ planr & $\begin{array}{l}\text { Involvement of the interest management groups in the process of strategic } \\
\text { ning }\end{array}$ \\
\hline & $\checkmark$ & Desire and willingness of the personnel for greater efforts \\
\hline & $\checkmark$ & Self-reliance between the personnel \\
\hline & $\checkmark$ & Strengthen of the spirit of cooperation \\
\hline & $\checkmark$ & Sense of loyalty of the personnel towards the organization \\
\hline & $\checkmark$ & Establishment of Organizational coordination \\
\hline \multirow[t]{9}{*}{ Organization culture } & $\checkmark \quad$ perso & $\begin{array}{l}\text { Providing new ideas, offering effective proposals to solving the problems by the } \\
\text { onnel in the process of strategic planning }\end{array}$ \\
\hline & $\checkmark \quad$ org & $\begin{array}{l}\text { Unification of the objectives of the individuals with the objectives of the } \\
\text { nization in the process of strategic planning }\end{array}$ \\
\hline & $\checkmark$ & Risk tolerance of the personnel in the process of strategic planning \\
\hline & $\checkmark$ & The unification and alliance in the successful process of strategic planning \\
\hline & $\checkmark$ & Relation of the management with the personnel \\
\hline & $\checkmark$ & Control in the successful process of strategic planning \\
\hline & $\checkmark$ & Bonus system based on the performance of personnel \\
\hline & $\checkmark \quad$ planı & $\begin{array}{l}\text { The tolerance of personnel when facing contradictions in the process of strategic } \\
\text { ning }\end{array}$ \\
\hline & $\checkmark$ & Paying attention to the communication models in the process of strategic planning \\
\hline
\end{tabular}




\section{Methodology}

\subsection{Research Questions}

This research has been conducted to determine the factors effective in the success of strategic planning in project management. For this purpose, one question is provided in the following:

Question: How important are the factors effective in the success of strategic planning?

\subsection{Research Method}

Several factors effective in the success of strategic planning have been introduced for answering the question of this research. Moreover, several indices have been provided for each factor. The statistical population of this research consists of the managers, consultants, and experts. For the collection of data, a questionnaire has been used, and the variables are measured using Likert scale, in which the variables are scored using the five-level items of strongly disagree, disagree, neither agree nor disagree, agree, strongly agree.

\section{Discussion of the Findings}

Strategic planning in project management is indispensable. The emphasis of strategic planning in an enterprise's project management is not to discuss how to manage a single project by a project manager, but to focus on building a project management environment of the enterprise. This helps to support and supervise all project managers. It is necessary to make the utmost of enterprise resources to manage each project and enhance the overall operation and management capacity of the enterprise. Strategic planning of an enterprise's project management refers to the corporate strategies performed by the top management in formulating project management. The objective is to get all projects well performed. Simply speaking, the primary work of strategic planning in project management is to establish a set of standard methods for project management and incorporate these methods into the business flows, which will finally form an operation and management system with the center of project management. Incorporation of project management methods into business flow will provide opportunities for success of corporate projects in a comprehensive way. Meanwhile, other sections of the enterprise will do their work centering on the project with a coordinate tune.

Implementation of strategic planning in project management of a project-based enterprise is a complicated process. Considering the actual conditions of the enterprise, this process may be finished with half a year to two years duration of time. Generally, the implementation process of a project's strategic planning can be classified into three stages. Firstly, the top management of an enterprise sets a target for the enterprise to implement the strategies of project management by means of strategic seminar and makes the commitment to implement strategies of project management. Secondly, the enterprise sets up project management methods and business flow with focus on project management and makes plans for corresponding organizational role and performance assessment. Thirdly, the process of implementing the business flow with focus on project management is one stepping from the simple to the complicated. In the process of building an enterprise's project management methods and business flow, the top management and business personnel further communicate as for selection of corporate projects and the target of project implementation. Promotion and application of project management methods and business flow will enhance the project management level of the enterprise in an overall perspective and will also elevate the operational and management capacity of the enterprise.

\section{Conclusion and Recommendations}

\subsection{Conclusion}

According to the results of this research, the involvement of top management, involvement of team personnel, knowledge of top management of strategic planning, and organizational culture are the factors having effect on the success of strategic planning in project management. The results of this research show that organizational culture, knowledge of top management of strategic planning involvement of top management, and involvement of team personnel are respectively the most important factors effective in the success of strategic planning. According to the results of this research, the following recommendations are provided.

\subsection{Recommendations}

1) Allocate of sufficient financial and organizational resources to facilitate the objectives of project and explain its importance to the personnel

2) Hold regular meetings attended by top managers of the company and the project manager responsible for strategic planning to determine the strategic policies of strategic planning. 
3) The top management should act as a supervisory member in the strategic planning project to meet the objectives of the project and solve any contingent disputes.

4) Hold committees composing of the key managers and directors of the organization to underpin their role in the project of strategic planning.

5) Hold committees consisting of key experts of the different sections of the organization to participate in the strategic planning project in order to facilitate the implementation of the project, not to resist against the changes that may arise due to the implementation of strategic planning project, and involve the different departments of the organization in the strategic planning.

6 Pave the way for an appropriate relation between the directors and personnel playing a role in the projects of strategic planning.

7) Vest officially powers and authorities to the personnel for the implementation of strategic planning projects.

8) Notify officially the strategic planning project to all managers and directors of the departments by the highest authority of the organization to bind them for the project.

9) The personnel should be involved in the process of strategic planning to prevent their resistant against the changes that may arise due to the strategic planning and increase the agreement of personnel.

10) Hold meetings attended by the project team of strategic planning to remove any ambiguities.

\section{References}

Alvani, S. M. (1995). Public Management (4th ed.). Nashr-e Ney Publishing House.

Bruce, A., \& Longden, K. (2004). Strategic Thinking. Trans. Said Alimirzaei.

Haines, S. G. (1997). Success in Strategic Planning. Trans. Javad Kasravi. Industrial Managers Association Publishing House.

Prathibha, V., \& Kevine, B. (2010). Practical Techniques for strategic planning in Health Care organizations. PEJ, p. 46.

Retrieved from https://pmtips.net/article/critical-success-factors-for-strategic-planning

Richard, W. O. (2005). The Evolution of Business Strategy. Journal of Business Strategy.

Ricky, L. (2001). Strategic and Organizational Structure. Trans. Ali Aghili. Ney Publishing House.

Sa'adat, E. (1996). Human Resource Management. Samt Publishing House.

Sha'ni, M. (2004). Strategic Planning for Managers. Industrial Management Organization.

Shokouhi, A., \& Nesari, M. (2002). Strategic Planning: A Manual for Implementation and Development. Bist-e Esfahan Publishing House.

Shokri, M. (2001). A Study of Strategic Management. Management Journal.

Stoner, E. F., \& Freema, E. (1996). Planning and Organizing. Trans. Mohammad A'rabi \& Ali Parsaian. Tehran: Commercial Research and Study Institute.

Zomorodian, M. (1994). Organizational Culture and Productivity. Administrative Change Quarterly, Special Issue.

\section{Copyrights}

Copyright for this article is retained by the author(s), with first publication rights granted to the journal.

This is an open-access article distributed under the terms and conditions of the Creative Commons Attribution license (http://creativecommons.org/licenses/by/4.0/). 